\title{
NOVO NALAZIŠTE I SINTAKSONOMSKE ZNAČAJKE PASJEGA TRNA (Hippophaë rhamnoides L., Elaeagnaceae) U HRVATSKOJ
}

\author{
NEW LOCALITIES AND SYNTAXONOMIC CHARACTERISTICS \\ OF SEA BUCKTHORN (Hippophaë rhamnoides L., Elaeagnaceae) \\ IN CROATIA
}

Jozo FRANJIĆ ${ }^{1}$, Gabrijel HORVAT², Daniel KRSTONOŠIĆ ${ }^{1}$

\begin{abstract}
Sažetak
Pasji je trn glacijalni relikt, koji se je nakon povlačenja ledenoga pokrova širio prema sjeveru i višim planinskim položajima. U Hrvatskoj je bio rasprostranjen u Međimurju i u Podravini (uz Muru i Dravu - Legrad, Bukovec, Dubrava, Križovljan-grad). Vrlo je rijedak i u uzgoju ili subspontano proširen, te se još navodi i za područje Samobora, Skradina, a u uzgoju je još zabilježen u Botaničkome vrtu Prirodoslovno-matematičkoga fakulteta Sveučilišta u Zagrebu, Nespešu, Starom Brestju (Sesvete), uz brzu cestu Sv. Helena-Bjelovar i u Park-šumi Adica u Vukovaru. Tijekom prve polovice 20. stoljeća nije bilo nikakvih novih podataka o rasprostranjenosti pasjega trna u Hrvatskoj, a u drugoj polovici 20. stoljeća, tijekom fitocenoloških istraživanja vegetacije u priobalnome pojasu rijeke Drave u široj varaždinskoj okolici Trinajstić $(1964,1994)$ bilježi nekoliko grmova, bez posebne fitocenološke pripadnosti. Za Hrvatsku prve podatke o fitocenološkim značajkama vrste $H$. rhamnoides donosi Trinajstić (2006) i to na osnovi jedne fitocenološke snimke iz koje se može jasno razabrati da ona prema svom florističkom sastavu pripada u sintaksonomskom smislu as. Hippophao-Berberidetum Moor 1958.

Najnovijim istraživanjima sukcesije vegetacije u Podravini, 26. lipnja 2015. godine utvrđeno je novo nalazište vrste H. rhamnoides sjeverno od sela Veliki i Mali Bukovec (46.3070540, 16.7275400). Napravljena je jedna fitocenološka snimka (Tab. 1). Analizom fitocenološke snimke vidljivo je da je ona bogatija vrstama (25:15) od fitocenološke snimke Trinajstić-a (2006) i vrlo je slična snimkama Moor-a (1958). Dosad je Trinajstić-ev (2006) nalaz pasjega trna iz 1966. godine bio posljednji zabilježeni nalaz ove vrste u Hrvatskoj. Kako su hidrološkim zahvatima uništena staništa i kako je pasji trn nestao s toga prostora novi nalaz pasjega trna i nalaz as. Hippophao-Berberdetum Moor 1958 (Berberidion vulgaris Br.-Bl. 1950) su jedini postojeći prirodni nalazi. Iz tih razloga potrebno je naglasiti da je hrvatska flora sada bogatija za jednu vrstu prirodno rasprostranjenu, a i vegetacija Hrvatske je bogatija za jednu asocijaciju kojima treba dati odgovarajuće prirodoznanstveno značenje.
\end{abstract}

KLJUČNE RIJEČl: novo nalazište, pasji trn, Hippophaë rhamnoides, Hippophao-Berberidetum, Hrvatska

${ }_{1}$ Prof. dr. sc. Jozo Franjić, franjic@sumfak.hr; Dr. sc. Daniel Krstonošić, dkrstonosic@sumfak.hr, Sveučilište u Zagrebu - Šumarski fakultet, Svetošimunska 25, HR-10000 Zagreb,

${ }^{2}$ Dr. sc. Gabrijel Horvat, gabrijel.horvat@hrsume.hr, Hrvatske šume d.o.o. Zagreb, UŠP Koprivnica, Šumarija Ludbreg, Koprivnička 2, 42230 Ludbreg

Autor za korespondenciju: Jozo Franjić, franjic@sumfak.hr 


\section{UVOD}

\section{INTRODUCTION}

Pasji je trn glacijalni relikt, koji se je nakon povlačenja ledenoga pokrova širio prema sjeveru i višim planinskim položajima. Danas je rasprostranjen na području Europe i Azije. Nastanjuje šljunkovite i pješčane riječne sprudove (dine) u sastavu zajednice Hippophao-Berberidetum Moor 1958. Gledano u europskim razmjerima, svojta raste i na pješčanoj podlozi unutar rjeđih šumskih, najčešće borovih sastojina.

Prirodno je bio rasprostranjen u Međimurju i u Podravini (uz Muru i Dravu - Legrad, Bukovec, Dubrava, Križovljangrad), (usp. Schlosser i Vukotinović 1869; Pichler 1891; Hirc 1906; Trinajstić 2006). Vrlo je rijedak i u uzgoju ili subspontano proširen, te se još navodi i za područje Samobora (Karavla 1972), Skradina (Host 1802), a u uzgoju je još zabilježen u Botaničkome vrtu Prirodoslovno-matematičkoga fakulteta Sveučilišta u Zagrebu, Nespešu i Starom Brestju (Sesvete), (usp. Franjić 2015). Još je zabilježen i uz brzu cestu Sv. Helena-Bjelovar (Šincek 2015, prema Nikolić-u 2015) i u Parkšumi Adica u Vukovaru (Bilić 2014, prema Nikolić-u 2015).

Tijekom prve polovice 20. stoljeća nije bilo nikakvih novih podataka o rasprostranjenosti pasjega trna u Hrvatskoj, a u drugoj polovici 20. stoljeća, tijekom fitocenoloških istraživanja vegetacije u priobalnome pojasu rijeke Drave u široj varaždinskoj okolici Trinajstić $(1964,1994)$ bilježi nekoliko grmova, bez posebne fitocenološke pripadnosti. Prigodom jedne ekskurzije u sklopu terenske nastave sa studentima prve godine Šumarskoga fakulteta iz Zagreba, u proljeće 1966. godine Trinajstić pronalazi malene sastojine pasjega trna u priobalnom dijelu Drave kod Križovljan-grada. Kako dalje navodi, čitavo priobalno područje rijeke Drave zapadno od Varaždina pod kraj 20. stoljeća, izgradnjom brane preobraženo je u veliko akumulacijsko jezero hidoelektrane „Varaždin". Na taj su način velike površine priobalja poplavljene i najvjerojatnije je niz rijetkih vrsta hrvatske flore uništen. Zbog toga, se od tada pa nadalje pasji trn (H. rhamnoides) vodi kao „regionalno izumrla svojta - RE” (usp. Nikolić i Topić 2005, 2005a; Pavletić 2005; Trinajstić 2006; Kovačić i dr. 2014; Nikolić 2015).

Listopadni je grm ili niže stablo visine do $6 \mathrm{~m}$. Korijen je snažno razvijen. Stabljika ima stršeće, gole i crvenosmeđe grane. Postrani ogranci razvijaju se u snažne trnove, a jednogodišnje grane prekrivene su srebrnastosivim dlakama. Listovi su izmjenični, linearnosuličasti, cjeloga ruba, srebrnastosivi, prekriveni zvjezdastim dlakama, dugi $5-7 \mathrm{~cm}, \mathrm{~s}$ peteljkom dugom oko $5 \mathrm{~mm}$. Dvodomna je vrsta, cvjetovi su sitni (oko $3 \mathrm{~mm}$ ), razvijaju se na prošlogodišnjim ograncima, cvjeta prije listanja ili istodobno, od III-V. mjeseca, a oprašuje se entomofilno. Ocvjeće je neugledno u obliku dvolapne čaške; ima četiri prašnika, u gustim kuglastim nakupinama; ima jedan tučak, s nadraslom, jednogradnom plodnicom i jednim sjemenim zametkom. Plod je narančastocrvena sočna boba, dužine $7-8 \mathrm{~mm}$; čvrsti endokarp obavija samo jednu sjemenku.

U prirodi se rasprostranjuje vegetativno ukorjenjivanjem izbojaka donesenih riječnim bujicama, a i sjemenkama koje raznose ptice (endoornitohorno). Plodovi su ukusne sočne bobe koje obiluju hranivim tvarima, bogate su vitaminom C, pa je biljka nekad služila u prehrani i u narodnoj medicini, a u nekim se zemljama zato preporučuje i njezin uzgoj. Od davnina su plodove dodavali hrani domaćih životinja, a i sam se naziv grč. hippophaë (konjski sjaj) može s tim povezati, zbog utjecaja vitamina $\mathrm{C}$ na sjaj konjske dlake. Kao pionirska vrsta, primjenjuje se i za učvršćivanje ogoljelih terena, pa se na takvim mjestima i sadi, a zabilježeni su i slučajevi naturalizacije. Uzgaja se i u vrtlarstvu kao ukrasni grm. Jestiva, medonosna i ljekovita biljka.

U literaturi se navodi osim tipične podvrste (ssp. rhamnoides), koja se razvija na prirodnim dinama Atlanskoga oceana, još dvije podvrste ssp. carpatica Rousi i ssp. fluviatilis Soest (usp. Ehrendorfer 1973; Trinajstić 2006), koje se razvijaju na riječnim sprudovima. Prema Tutin-u (1968) radi se samo o jednoj jedinstvenoj vrsti Hippophaë rhamnoides L.

Prve podatke o fitocenološkim značajkama vrste H. rhamnoides donose Gams (1927) i Aichinger (1933), a označavaju ih kao „Hippophaëtum rhamnoidis Binom Salici-Hippophaëtum uglavnom se odnosi na vrstu Salix repens i tipičnu podvrstu H. rhamnoides ssp. rhamnoides, ali i na vrstu Salix elaeagnos i H. rhamnoides ssp. fluviatilis (usp. Oberdörfer i Th. Müller 1992). Da riješi navedenu dilemu Moor (1958), tijekom sintaksonomske analize vegetacije riječnih dolina u Švicarskoj, između ostaloga analizira i sastojine u sklopu kojih se razvija H. rhamnoides. Tom prigodom Moor opisuje posebnu asocijaciju Hippophao-Berberidetum, i priključuje ju svezi Berberidion vulgaris. Floristički sastav novoopisane asocijacije Moor (1958: Tab. 25) prikazuje na temelju 16 fitocenoloških snimki.

Za Hrvatsku prve podatke o fitocenološkim značajkama vrste H. rhamnoides donosi Trinajstić (2006) i to na osnovi jedne fitocenološke snimke iz koje se može jasno razabrati da ona prema svom florističkom sastavu pripada u sintaksonomskom smislu asocijaciji Hippophao-Berberidetum Moor 1958. Fitocenološka snimka je napravljena uz obalu rijeke Drave kod Križovljan-grada i ima vrlo sličan floristički sastav kao i snimke Moor-a (1958).

\section{NOVO NALAZIŠTE I SINTAKSONOMSKE ZNAČAJKE PASJEGA TRNA (Hippophaë rhamnoides L.) NEW LOCALITIES AND SYNTAXONOMIC CHARACTERISTICS OF SEA BUCKTHORN (Hippophaë rhamnoides L.)}

Najnovijim istraživanjima sukcesije vegetacije u Podravini, 26. lipnja 2015. godine utvrđeno je novo nalazište vrste $H$. 
Tablica 1. Fitocenološke snimke as. Hippophao-Berberidetum Moor 1958. Table 1. Fitosociological relevé ass. Hippophao-Berberidetum Moor 1958.

\begin{tabular}{|c|c|c|c|}
\hline \multicolumn{2}{|l|}{ Broj snimke/No. relevé } & 1 & \multirow[b]{2}{*}{ 10.5. 1966.} \\
\hline Datum/Date & & 30. 6. 2015. & \\
\hline Nadmorska visina/Altitude (m) & & 140 & \multirow{5}{*}{$\begin{array}{l}\text { Uz obalu Drave kod } \\
\text { Križovljan-grada } \\
\text { (Trinajstić 2006) }\end{array}$} \\
\hline Izloženost/Exposition $\left({ }^{\circ}\right)$ & & 0 & \\
\hline Nagib/Inclination $\left({ }^{\circ}\right)$ & & 0 & \\
\hline \multirow{2}{*}{ Koordinate/Coordinates } & & 46.3070540 & \\
\hline & & 16.7275400 & \\
\hline Broj vrsta/No. species & & 25 & 15 \\
\hline Populus alba L. & A & 3 & \\
\hline Pinus sylvestris $\mathrm{L}$. & & 2 & 2 \\
\hline Alnus incana (L.) Moench & & & 1 \\
\hline Hippophae rhamnoides $\mathrm{L}$. & B & 4 & 3 \\
\hline Berberis vulgaris $\mathrm{L}$. & & 1 & 2 \\
\hline Crataegus monogyna Jacq. & & 2 & 1 \\
\hline Euonymus europaeus L. & & 1 & 1 \\
\hline Prunus spinosa L. & & + & 1 \\
\hline Salix purpurea L. & & & 1 \\
\hline Rhamnus catharticus $\mathrm{L}$. & & 1 & + \\
\hline Cornus sanguinea L. & & + & \\
\hline Humulus lupulus $\mathrm{L}$. & & + & \\
\hline Ligustrum vulgare $\mathrm{L}$. & & 1 & \\
\hline Prunus padus $\mathrm{L}$. & & + & \\
\hline Quercus robur $\mathrm{L}$. & & & + \\
\hline $\begin{array}{l}\text { Brachypodium pinnatum (L.) P. } \\
\text { Beauv. ssp. pinnatum }\end{array}$ & C & 4 & \\
\hline Galium mollugo L. & & + & 2 \\
\hline Rubus caesius $\mathrm{L}$. & & 2 & + \\
\hline Colchicum autumnale L. & & 2 & \\
\hline Solidago gigantea Aiton & & 1 & \\
\hline Teucrium chamaedrys $\mathrm{L}$. & & 1 & \\
\hline Aegopodium podagraria L. & & & 1 \\
\hline Veronica chamaedrys L. & & & 1 \\
\hline Allium sp. & & + & \\
\hline Asparagus tenuifolius $\mathrm{L}$. & & + & \\
\hline Briza media L. & & + & \\
\hline Dactylis glomerata L. & & + & \\
\hline $\begin{array}{l}\text { Dorycnium germanicum } \\
\text { (Gremli) Rikli }\end{array}$ & & + & \\
\hline Elymus repens (L.) Gould & & + & \\
\hline Vicia cracca L. & & + & \\
\hline Stellaria holostea L. & & & + \\
\hline
\end{tabular}

rhamnoides sjeverno od sela Veliki i Mali Bukovec (46.3070540, 16.7275400). Biljke su brojne i u dobroj su kondiciji. Naknadno, tijekom rujna 2015. godine utvrđeno je da se radi o samo muškim primjercima različite dobi i veličine. Čitava je sastojina formirana u obliku šumskoga ruba, tako da se više i starije jedinke nalaze u sklopu šume ili na nje- nom rubu, a niže i mlađe se javljaju na livadi koja je ograničene površine (cca $100 \times 30-40$ m). Više i starije jedinke koje se nalaze u zasjeni krošanja viših biljaka (Populus alba L. i Pinus sylvestris L.) i rastu uz druge grmaste vrste (Crataegus monogyna Jacq., Euonymus europaeus L., Berberis vulgaris L., Ligustrum vulgare L.) su u lošijoj kondiciji i polako se povlače (usp. sl. 1-6). U šumi su zamijećeni stariji suhi primjerci koji se nalaze pod krošnjama viših stabala (Populus alba, Pinus sylvestris). Na livadi se vegetativno iz korijenja razvijaju brojne nove jedinke i za pretpostaviti je da se radi o jednome klonu. Livada se nalazi u sukcesiji, što je vidljivo iz velike pokrovnosti vrste Brachypodium pinnatum (L.) P. Beauv. ssp.pinnatum i pojavi grmastih vrsta (H. rhamnoides, Crataegus monogyna, Prunus spinosa, Populus tremula i dr.).

Nakon ovoga pronalaska obavljen je detaljan pregled vegetacije svih do sada poznatih nalazišta pasjega trna. Tako su tijekom lipnja, srpnja i rujna 2015. godine terenskim istraživanjima provjerni literaturni navodi - Schlosser i Vukotinović (1869), Pichler (1891), Hirc (1906); Trinajstić (1964, 1994, 2006), na kojima nije utvrđena prisutnost vrste $H$. rhamnoides. Zasad je novo nalazište nedaleko od Velikoga i Maloga Bukovca jedino prirodno nalazište u Hrvatskoj.

Napravljena je jedna fitocenološka snimka (tab. 1; sl. 1-6) iz čijega je flornoga sastava vidljivo da je ona bogatija vrstama (25: 15) od fitocenološke snimke Trinajstić-a (2006) koja je napravljena kod Križovljan-grada 1966. godine i vrlo slična snimkama Moor-a (1958).

\section{RASPRAVA I ZAKLJUČAK DISCUSSION AND CONCLUSION}

Tijekom istraživanja sukcesije vegetacije u Podravini, 26. lipnja 2015. godine utvrđeno je novo ili je potvrđeno do sada poznato nalazište vrste $H$. rhamnoides sjeverno od sela Veliki i Mali Bukovec (46.3070540, 16.7275400). Biljke su brojne i u dobroj su kondiciji, a naknadno tijekom rujna 2015. godine utvrđeno je da se radi o muškim primjercima različite dobi i veličine. Također su u šumi zamijećeni suhi primjerci koji se nalaze pod krošnjama viših stabala ( $P \circ p u-$ lus alba, Pinus sylvestris).

Budući da je vrlo teško locirati Kitaibelove navode (usp. Schlosser i Vukotinović 1869; Hirc 1906; Trinajstić 2006; Franjić 2015; Nikolić 2015) i kako gotovo 150 godina nitko nije potvrdio niti opovrgnuo te navode, te kako se u aktualnoj literaturi navodi da vrsta ima status „regionalno izumrla svojta - RE" (usp. Nikolić i Topić 2005, 2005a; Pavletić 2005; Trinajstić 2006; Kovačić i dr. 2014; Nikolić 2015) za pretpostaviti je da se radi o novome nalazištu. Vrlo je mala vjerojatnost da se vrsta održala kroz vrlo dugi niz godina. Bez obzira na sve, radi se o vrlo vrijednome nalazu.

Budući da se radi o heliofilnoj vrsti koja ne podnosi zasjenu viših stabala (Populus alba, Pinus sylvestris) i da kao pionir- 

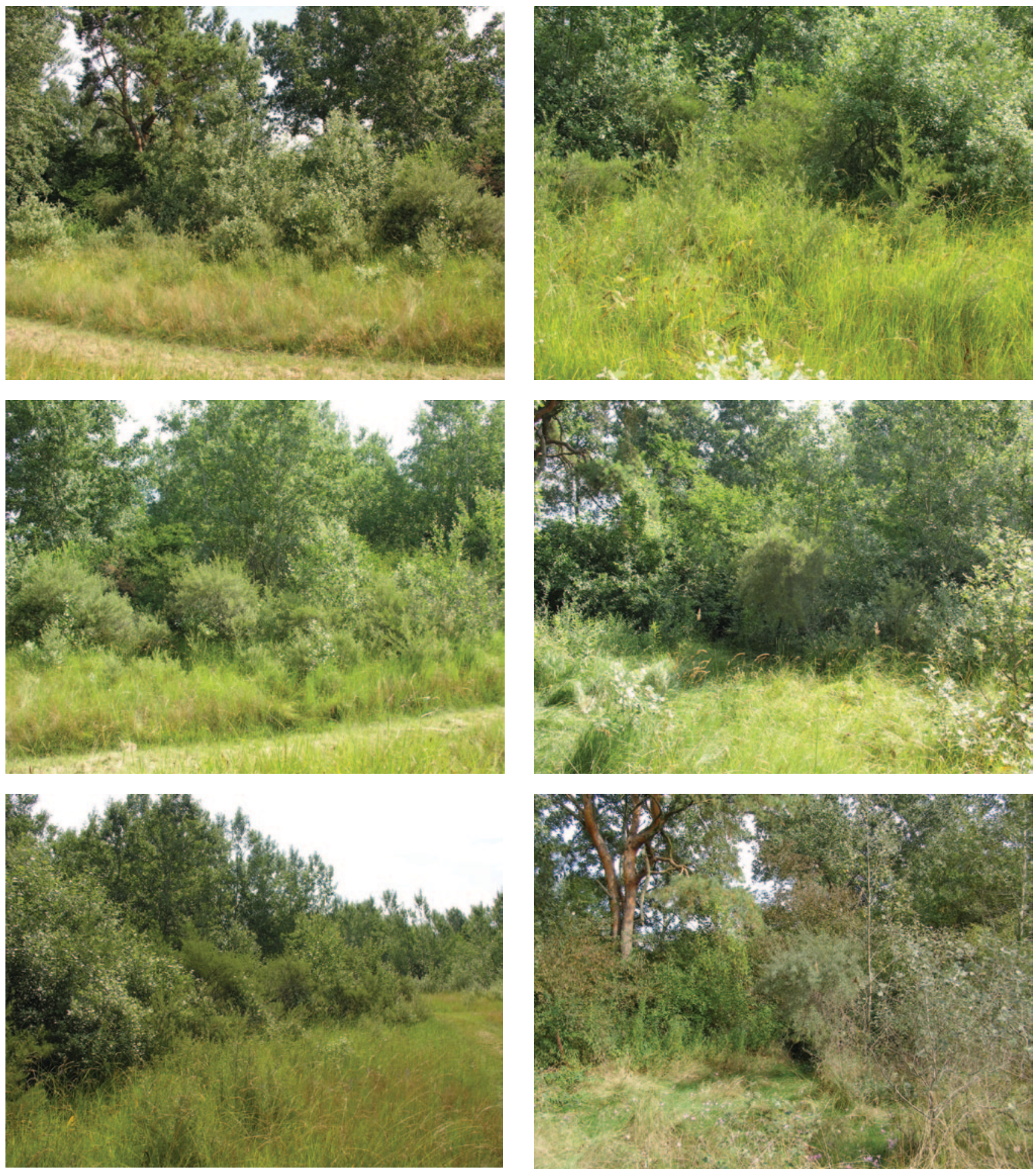

Slika 1-6. Novo nalazište pasjega trna (Hippophaë rhamnoides L.) i zajednice Hippophao-Berberdetum Moor 1958, Bukovec. Figure 1-6. New localities of sea buckthorn (Hippophaë rhamnoides L.) and ass. Hippophao-Berberdetum Moor 1958, Bukovec.

ska vrsta nije konkurentna drugim grmastim vrstama s kojima raste (Crataegus monogyna, Euonymus europaeus, Berberis vulgaris, Ligustrum vulgare) jedinke su ove vrste vrlo ugrožene. Tako su zamijećeni suhi stariji primjerci koji se nalaze pod krošnjama viših stabala (Populus alba, Pinus sylvestris) unutar šume. Kako je čitava sastojina formirana u obliku šumskoga ruba, tako da se više i starije jedinke nalaze u sklopu šume ili na njenom rubu, a niže i mlađe se javljaju na livadi koja je ograničene površine $(\mathrm{cca} 100 \times 30-40 \mathrm{~m})$ za očekivati je da će čitava livada vrlo brzo (za 5-10 godina) zarasti u šumsku vegetaciju i da će i ovo nalazište biti ugroženo te s vremenom nestati. Zbog svega toga neophodno je žurno poduzeti sve potrebne radnje kako bi se očuvalo stanište i jedino prirodno nalazište pasjega trna u Hrvtaskoj. 
Kako se radi samo o muškim jedinkama pasjega trna i vjerojatno samo o jednome klonu, te kako se vrsta održava isključivo vegetativnim razmnožavanjem, vrlo je mala vjerojatnost da se ona proširi na drugo područje, te je zbog toga njen opstanak još upitniji. Zbog toga bi trebalo obaviti dodatna istraživanja i poduzeti žurne mjere zaštite.

Analizom fitocenološke snimke (Tab. 1) vidljivo je da je ona bogatija vrstama (25: 15) od fitocenološke snimke Trinajstić-a (2006) koja je napravljena kod Križovljan-grada 1966. godine i vrlo je slična snimkama Moor-a (1958). Do sada je Trinajstićev (2006) nalaz pasjega trna iz 1966. godine bio posljednji zabilježeni nalaz ove vrste u Hrvatskoj. Kako su hidrološkim zahvatima uništena staništa i kako je pasji trn nestao s toga prostora, novi nalaz pasjega trna i nalaz as. Hippophao-Berberdetum Moor 1958 (Berberidion vulgaris Br.-Bl. 1950) su jedini postojeći prirodni nalazi. Iz tih razloga potrebno je naglasiti da osim što je hrvatska flora bogatija za jednu vrstu prirodno rasprostranjenu i vegetacija Hrvatske je bogatija za jednu asocijaciju kojima treba dati odgovarajući prirodoznanstveno značenje.

\section{LITERATURA}

\section{REFERENCES}

- Aichinger, E., 1933: Vegetationskunde der Karaanken. Pflanzensoziologie 2. Jena.

- Ehrendorfer, 1973: Liste der Gatasspflanzen Miteleuropas. Ed. 2. Gustav Fischer. Stuttgart.

- Franjić, J., 2015: Pasji trn (Hippophaë rhamnoides L., Elaeagnaceae) u flori Hrvatske. Šum. list 139(5-6): 274-275.

- Gams, H., 1927: Von den Follaterres zur Dent de Mordes. Beitr. Geobot. Landesaufn. Schweiz, 15.

- Hirc, D., 1906: Revizija hrvatske fore. Rad Jugosl. akad. 167: 8-128.

- Kovačić, S., D. Sandev, D. Mihelj, V. Stamenković, 2014: Win some, lose some - statutorily strictly protected indigenous plant species in the Botanical garden of the Faculty of science (University of Zagreb, Croatia). Nat. Croat. 23(2): 415-423.
- Moor, M., 1958: Pflanzengesellschaften schweizerischer Flussauen. Mitt. Schweiz. Anst. Forstl. Versuchsw. 34(4): 221-360.

- Nikolić, T. (ur.), 2015: Flora Croatica baza podataka (http://hirc. botanic.hr/fcd). Sveučilište u Zagrebu - Prirodoslovnomatematički fakultet (datum pristupa: 20.10.2015).

- Nikolić, T. J. Topić, 2005: Kategorije ugroženosti i primjenjeni kriteriji. U: Nikolić, T., J. Topić (eds.): Crvena knjiga vaskulame flore Hrvatske, 1-79. Državni zavod za zaštitu prirode Republike Hrvatske.

- Nikolić, T., J. Topić, 2005a: 13. Regionalno izumrle svojte: 80-101. U: Nikolić, T., J. Topić (eds.): Crvena knjiga vaskulame flore Hrvatske. Državni zavod za zaštitu prirode Republike Hrvatske.

- Oberdörfer, E., Th. Müller, 1992: Ordnung: Prunetalia spinosae Tx. 52. U: Oberdörfer, E.: Süddeutsche Pflanzengesellschaften 2(4): 82-106. Gustav Fischer. Jena-Stuttgart-New York.

- Pavletić, Zi., 2005: Hippophäe rhamnoides L. U: Nikolić i Topić (eds.): Crvena knjiga vaskulame flore Hrvatske 13: 99-111. Državni zavod za zaštitu prirode Republike Hrvatske.

- Pichler, A., 1891: Biljevni sag okolice varaždinske. Izvješæe Kralj. Vel. Gimn. Varažd. 190(91): 3-41.

- Schlosser, J., LJ. Vukotinović, 1869: Flora Croatica. Zagrabiae.

- Trinajstić, I., 1964: Vegetacija obalnog područja rijeke Drave u široj okolici Varaždina. Magistarski rad - Sveučilište u Zagrebu - Prirodoslovno-matematički fakultet. Zagreb.

- Trinajstić, I., 1994: Hippophäe rhamnoides L. U: Šugar, I. (ed.): Crvena knjiga biljnih vrsta Republike Hrvatske, 253-254. Ministarstvo graditeljstva i zaštite okoliša, Zavod za zaštitu prirode. Zagreb.

- Trinajstić, I., 2006: Fitocenološke značajke as. Hippophao-Berberidetum Moor 1958 (Berberidion vulgaris) u Hrvatskoj. Šum. list 130(9-10): 421-426.

- Tutin, T. G., 1968: Hippophäe L. U: Tutin, T. G., V. H. Heywood (eds.): Flora Europaea 2: 261. Cambridge University Preess.

- Tüxen, R., 1952: Hecken und Gebüsche. Mitt. Geogr. Ges. Hamburg 50: 80-117.

- Wirth, J. M., 1993: Rhamno-Prunetea. U: Mucina, Grabherr, Walnöfer (eds.): Die Pflanzengesellschaften Österreichs 3: 6084. Gustav Fischer. Jena-Stuttgart-New York.

\section{Summary}

Common sea-buckthorn is a glacial relict, which was, after the last glaciation, spreading to the north and higher mountain positions. In Croatia, it was widespread in Međimurje and Podravina (near Mura and Drava river - Legrad, Bukovec, Dubrava, Križovljan-grad). It is very rare in cultivation or sub-spontaneous spread, some sites are referred to the Samobor and Skradin area, and cultivated it can be found in the botanical garden of the Faculty of Science, University of Zagreb, Nepeš, Staro Brestje (Sesvete), by the road Sv. HelenaBjelovar and in the Forest Park Adica in Vukovar. During the first half of the 20th century there was no new information on the distribution of sea buckthorn in Croatia, and in the second half of the 20th century, during the phytosociological survey of vegetation in the coastal zone of the river Drava in the wider Varaždin surroundings Trinajstić $(1964,1994)$ records several shrubs, without special phytosociological affiliation. As for Croatia, the first data on phytosociological features of the species H. rhamnoides brings Trinajstić (2006), based on one phytosociological relevé which, according to its floristic composition, in syntaxonomic terms belongs to the Ass. Hyppophao-Berberidetum Moor 1958.

The latest research on vegetation succession in Podravina, 26th of June 2015, showed a new locality of $H$. rhamnoides, north of the villages Veliki and Mali Bukovec (WGS84 Lat: 46.307054, Long: 16.727540). One 
phytosociological relevé was made (Tab. 1). The analysis of the relevé shows a greater species richness (25, 15) compared to the one of Trinajstićs (2006) and is very similar to the relevé of Moore's (1958). So far Trinajstić-s (2006) finding of sea-buckthorn in 1966 was the last recording of this species in Croatia. As the hydrological interventions destroyed the habitats, causing the sea-buckthorn to disappear from this area, the new records of sea-buckthorn and Ass. Hyppophao-Berberdetum Moor 1958 (Berberidion vulgaris BraunBlanquet 1950) are the only existing natural findings there. For these reasons, it should be noted that the Croatian flora is now richer for one naturally spread species, as well as the vegetation of Croatian is richer for one association which should be given an adequate importance in natural science.

KEY WORDS: new locality, Sea Buckthorn, Hippophaë rhamnoides, Hippophao-Berberidetum, Croatia 